\title{
Mesenchymal stem cells as a potential therapy for COVID-19
}

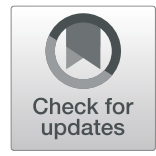

Shan Liu ${ }^{1 \dagger}$, Danyi Peng ${ }^{2 \dagger}$, Huijun $\mathrm{Qiu}^{2}$, Ke Yang ${ }^{3}$, Zhou Fu ${ }^{2,3^{*}}$ and Lin Zou ${ }^{1,3^{*}}$

\begin{abstract}
The outbreak of 2019 novel coronavirus disease (COVID-19) worldwide is becoming rapidly a major concern. The number of severe cases has increased dramatically worldwide, while specific treatment options are scarce. The main pathologic features of severe or critical COVID-19 were consistent with acute lung injure (ALI)/acute respiratory distress syndrome (ARDS), characterized by cellular fibromyxoid exudates, extensive pulmonary inflammation, pulmonary edema, and hyaline membrane formation. Mesenchymal stem cells (MSCs) can balance the inflammatory response and has been mentioned to be effective on ALI/ARDS from both infectious and noninfectious causes previously, presenting an important opportunity to be applied to COVID-19. In this commentary, we summarize the clinical trials of MSCs treatments on ALI/ARDS and raise MSCs as a hopefully alternative therapy for severe or critical COVID-19.
\end{abstract}

Keywords: COVID-19, ALI, ARDS, MSCS

\section{Background}

Severe acute respiratory syndrome coronavirus 2 (SARSCoV-2) disease (COVID-19) is a newly-recognized infectious disease. It has rapidly transmitted and become a major concern all over the world. As of April 3, 2020, the total number of patients has risen sharply to 1,033 , 060 worldwide, with 54,677 (5.29\%) deaths [1]. Apart from supportive care, oxygen supply in mild cases, and extracorporeal membrane oxygenation and low-dose corticosteroids in critical cases, intravenous remdesivir and convalescent plasma might be the effective potential therapy for SARS-CoV-2 infection. However, randomized clinical trials are needed to further evaluate the safety and efficacy of them in COVID-19 treatment. The

\footnotetext{
*Correspondence: fu_zhou79@aliyun.com; zoulin74@126.com

${ }^{\dagger}$ Shan Liu and Danyi Peng contributed equally to this work.

${ }^{2}$ Department of Respiratory Medicine; Ministry of Education Key Laboratory of Child Development and Disorders; China International Science and Technology Cooperation Base of Child Development and Critical Disorders, Children's Hospital of Chongqing Medical University, Chongqing, China ${ }^{1}$ Center for Clinical Molecular Laboratory Medicine/Newborn Screening Center National Clinical Research Center for Child Health and Disorders, Children's Hospital of Chongqing Medical University, Chongqing, China Full list of author information is available at the end of the article
}

specific and novel therapeutic methods for this disease are still being explored.

\section{Main text \\ The main pathologic features of severe or critical COVID-19 contain hypoxemia, diffuse alveolar damage with cellular fibromyxoid exudates, extensive pulmonary inflammation, pulmonary edema, and hyaline membrane formation. The pathologic changes are similar with acute lung injure (ALI)/acute respiratory distress syndrome (ARDS) [2], also observed in SARS and Middle Eastern respiratory syndrome (MERS) coronavirus infection. However, more serious inflammatory exudation, pul- monary edema and inflammatory cytokine storm, and milder pulmonary fibrosis and consolidation were ob- served in severe or critical COVID-19 than those in SARS. Mesenchymal stem cells (MSCs), which originate from bone marrow, fat, umbilical cord, placenta, and other tissues, have abundant supply, differentiation po- tential, powerful immunoregulation, and endogenous re- pair mechanisms. As one of the most widely studied adult stem cells in regenerative medicine, MSCs produce}


meaningful therapeutic outcomes for the treatment of pulmonary, cardiovascular, neurological, liver, and kidney diseases. The immune-regulation of MSCs depends mainly on modulating activation and effector function of immune cells, suppressing lung-infiltrated cells, and enhancing the resolution of pulmonary edema [3]. The incomplete revealed mechanisms but critical roles of MSCs on anti-inflammatory effects imply that MSCs is a potential therapy for severe and critical COVID-19.

MSCs have been identified to efficiently cure ALI/ ARDS from both infectious and noninfectious causes, mediated primarily by paracrine mechanisms based on the released extracellular vesicles (EVs), such as microvesicles and exosomes [4]. In the cargo of the EVs, more than 850 unique gene products and more than $150 \mathrm{miR}$ NAs have been identified by mass spectrometry analysis. Either the miRNAs or the transcripts are enriched in the regulators of the immune system $[5,6]$.

Detailed, MSCs can alter the behavior of both adaptive and innate immune cells. They can release keratinocyte growth factor, prostaglandin E2, granulocyte-macrophage colony-stimulating factor, and IL-6 and IL-13 to facilitate the phagocytosis and alternative activation of alveolar macrophage, alter the cytokine secretion profile of

Table 1 The clinical trials of MSCs on ALI/ARDS

\begin{tabular}{|c|c|c|c|c|c|c|}
\hline No. & Study name (NCT number) & Starting date & Phase & MSCs type and dose & $\begin{array}{l}\text { The origin of } \\
\text { ALI/ARDS }\end{array}$ & Key findings/study status \\
\hline 1 & $\begin{array}{l}\text { Adipose-derived MSCs in } \\
\text { ARDS (NCT 01902082) }\end{array}$ & Nov 2012 & Phase $1 \mathrm{~b}$ & $\begin{array}{l}\text { Intravenous infusion of human } \\
\text { adipose MSCs, with } 1 \times 10^{6} / \mathrm{kg}\end{array}$ & Unknown & $\begin{array}{l}\text { Low dose of } 1 \times 10^{6} \\
\text { adipose-derived } \mathrm{MSCs} / \mathrm{kg} \\
\text { was well tolerated }\end{array}$ \\
\hline 2 & MSCs for ARDS (NCT 01775774) & Jul 2013 & Phase $1 \mathrm{~b}$ dose-escalation & $\begin{array}{l}\text { Intravenous infusion of hBM MSCs, } \\
\text { with } 1,5 \text {, or } 10 \times 10^{6} / \mathrm{kg}\end{array}$ & $\begin{array}{l}\text { Pneumonia or } \\
\text { sepsis or aspiration } \\
\text { or preeclampsia }\end{array}$ & $\begin{array}{l}\text { All MSCs doses well } \\
\text { tolerated } \\
\text { No adverse effects } \\
\text { detected }\end{array}$ \\
\hline 3 & $\begin{array}{l}\text { MSCs for treatment of ARDS } \\
\text { in stem cell transplant patients } \\
\text { (NCT 02804945) }\end{array}$ & Feb 2017 & Phase 2 & $\begin{array}{l}\text { By vein with a maximum dose of } \\
3 \times 10^{6} \text { cell/kg one time at day } 1\end{array}$ & Unknown & Completed \\
\hline 4 & $\begin{array}{l}\text { Clinical study to assess the } \\
\text { safety and preliminary efficacy } \\
\text { of HCR040 in ARDS } \\
\text { (NCT 04289194) }\end{array}$ & Dec 2019 & Phase 1-2 & $\begin{array}{l}\text { Intravenous administration of } \\
\text { allogeneic adipose-derived adult } \\
\text { MSCs expanded and pulsed with } \\
\mathrm{H}_{2} \mathrm{O}_{2} \text {, the maximum tolerated dose } \\
\left(1 \text { or } 2 \times 10^{6} \text { cells } / \mathrm{kg}\right)\end{array}$ & Unknown & Active, not recruiting \\
\hline 5 & $\begin{array}{l}\text { Repair of ARDS by stromal cell } \\
\text { administration (NCT 03042143) }\end{array}$ & Jan 2019 & Phase $1-2$ & $\begin{array}{l}\text { Human UC-derived CD362-enriched } \\
\text { MSCs, the maximum tolerated dose } \\
\text { from phase } 1 \text { trial }\end{array}$ & Unknown & Recruiting \\
\hline 6 & $\begin{array}{l}\text { UC-MSCs therapy in ARDS (NCT } \\
\text { 03608592) }\end{array}$ & Jun 2018 & Not applicable & $\begin{array}{l}\text { Intravenous infusion of UC-MSCs, } \\
\text { dose } 1 \times 10^{6} / \mathrm{kg}\end{array}$ & Unknown & Recruiting \\
\hline 7 & $\begin{array}{l}\text { UC-MSCs therapy in ALI (NCT } \\
\text { 024444455) }\end{array}$ & May 2015 & Phase $1-2$ & $\begin{array}{l}\text { Intravenous infusion of hUB-MSCs, } \\
5 \times 10^{5} \text { cell/kg once a day, three } \\
\text { times }\end{array}$ & Unknown & Recruiting \\
\hline 8 & $\begin{array}{l}\text { MSCs in patients with ARDS (NCT } \\
\text { 02112500) }\end{array}$ & Feb 2014 & Phase 2 & intravenously infusion of MSCs & Unknown & Recruiting \\
\hline 9 & $\begin{array}{l}\text { UC-MSCs in the treatment of novel } \\
\text { coronavirus severe pneumonia } \\
\text { (NCT 04273646) }\end{array}$ & Feb 2020 & Not applicable & $\begin{array}{l}\text { Intravenous } 4 \text { times of UC-MSCs } \\
\left(0.5 \times 10^{6} \text { UC-MSCs/kg BW) at }\right. \\
\text { day } 1,3,5,7\end{array}$ & 2019-COVID & Not yet recruiting \\
\hline 10 & $\begin{array}{l}\text { A pilot clinical study on inhalation } \\
\text { of MSCs exosomes treating severe } \\
\text { novel coronavirus pneumonia (NCT } \\
\text { 04276987) }\end{array}$ & Feb 2020 & Phase 1 & $\begin{array}{l}5 \text { times aerosol inhalation of } \\
\text { MSCs-derived exosomes } \\
\left(2.0 \times 10^{8} \text { nano vesicles } / 3 \mathrm{ml}\right) \\
\text { at day } 1,2,3,4,5\end{array}$ & 2019-COVID & Not yet recruiting \\
\hline 11 & $\begin{array}{l}\text { UC-MSCs treatment for the 2019- } \\
\text { novel coronavirus pneumonia } \\
\text { (NCT 04269525) }\end{array}$ & Feb 2020 & Phase 2 & $\begin{array}{l}\text { Intravenous infusion of UC-MSCs } \\
\text { at day } 1,3,5,7\end{array}$ & 2019-COVID & Recruiting \\
\hline 12 & $\begin{array}{l}\text { Treatment with MSCs for severe } \\
\text { corona virus disease } 2019 \\
\text { (NCT 04288102) }\end{array}$ & Feb 2020 & Phase 1-2 & $\begin{array}{l}\text { Intravenous } 3 \text { times of MSCs } \\
\left(\mathrm{BW} \geq 70 \mathrm{~kg}, 4.0 \times 10^{7} \text { cells/time; }\right. \\
\left.\mathrm{BW}<70 \mathrm{~kg}, 3.0 \times 10^{7} \text { cells/time }\right) \\
\text { at day } 0,3,6\end{array}$ & 2019-COVID & Not yet recruiting \\
\hline 13 & $\begin{array}{l}\text { MSCs treatment for pneumonia } \\
\text { patients infected with } 2019 \text { novel } \\
\text { coronavirus (NCT 04252118) }\end{array}$ & Jan 2020 & Phase 1 & $\begin{array}{l}\text { Intravenous } 3 \text { times of MSCs } \\
3.0 \times 10^{7} \text { at day } 0,3,6\end{array}$ & 2019-COVID & Recruiting \\
\hline 14 & $\begin{array}{l}\text { Efficacy and safety of UC-MSCs for } \\
\text { the treatment of severe viral } \\
\text { pneumonia (NCT 04282928) }\end{array}$ & Feb 2020 & Phase 1 & $\begin{array}{l}\text { Intravenous infusion of definitive } \\
\text { HUC-MSCs }\left(1 \times 10^{6} \text { cells } / \mathrm{kg} \times\right. \\
\text { BW }(\mathrm{kg})\end{array}$ & $\begin{array}{l}\text { Influenza infection } \\
\text { viral pneumonia }\end{array}$ & Not yet recruiting \\
\hline
\end{tabular}

Abbreviations: MSCs mesenchymal stem cells, UC umbilical cord, UC-MSCs umbilical-cord-derived mesenchymal stem cells, $h B M$ MSCs human bone marrow-derived mesenchymal stem cells, BW body weight, NCT National Clinical Trial, ALI acute lung injure, ARDS acute severe respiratory failure, COVID nCoV infection severe pneumonia 
dendritic cell subsets, and decrease the release of interferon $\gamma$ from natural killer cells. IL-10, transforming growth factor $\beta$, and tryptophan catabolizing enzyme indoleamine 2,3-dioxygenase secreted from them can also suppress the proliferation of $\mathrm{T}$ cells and change the cytokine secretion profile of $\mathrm{T}$ cell subsets [7]. Moreover, the proliferation, differentiation, and chemotactic properties of B cells were impaired by MSCs as well [8]. Except for the immune regulatory effects, MSCs can enhance restoration of capillary barrier [9], inhibit bacterial growth [10], and restore alveolar ATP [11]. All the functions mentioned above might also be effective on ARDS induced by COVID-19 infection.

Some clinical trials for evaluating the efficacy and safety of MSC treatment on ALI/ARDS have begun. The inclusion criteria are according to the Berlin definition of ARDS [12] in common, while the START trial [13] had a more strict definition of moderate-to-severe ARDS with 4 categories: (1) positive pressure ventilation by an endotracheal or tracheal tube with a $\mathrm{PaO}_{2} / \mathrm{FiO}_{2}$ ratio of $<200$ with at least $8 \mathrm{~cm} \mathrm{H} \mathrm{H}_{2} \mathrm{O}$ positive end-expiratory airway pressure, (2) bilateral infiltrates consistent with pulmonary edema on the frontal chest radiograph, (3) without clinical evidence of left atrial hypertension or a pulmonary arterial occlusion pressure $\leq 18 \mathrm{mmHg}$, and (4) categories 1-3 must be present within a 24-h time period and at the time of enrolment. Exclusion criteria included patients younger than 18 years, pre-existing severe disease of any major organs, pregnancy, malignant disease, severe chronic respiratory disease, recent deep vein thrombosis or pulmonary embolism, human immunodeficiency virus infection, or if informed consent could not be obtained. In addition, the patients in whom more than $96 \mathrm{~h}$ since first meeting the Berlin definition for ARDS had also been excluded in the START trial to avoid enrolling patients with late ARDS. The completed clinical trials demonstrate that MSCs are well tolerated without adverse effects in ALI/ARDS (Table 1) [14, 15]. Additionally, acute graft-versus-host-disease (GVHD) is a lifethreatening complication of allogeneic hematopoietic stem cell transplantation due to its inflammatory storm. A meta-analysis revealed that infused MSCs could reduce acute GVHD grade and increase overall survival [16]. The therapeutic effects of MSCs on ALI/ARDS and GVHD with powerful inflammatory balance are solid proofs for the application of MSCs on other originated ALI/ARDS.

Furthermore, MSC treatment significantly ameliorates ALI/ARDS induced by H9N2 avian influenza virus [17] and H5N1 [18] in mice, and even influenza virus in pig [19], indicating the possible efficacy of MSCs on viral ALI/ARDS. Importantly, MSCs can cure the patients with severe refractory ARDS [20], who failed to improve after both standard life support measures including mechanical ventilation and additional measures including extracorporeal ventilation, pointing that MSC could be used for serious viral ALI/ARDS. Some Chinese research groups triggered the clinical studies on MSCs treating critical COVID-19 (Table 1). In the trigged clinical trials, the inclusion criteria for severe or critical COVID-19 include respiratory rate (RR) $\geq 30$ times/min, pulse oxygen saturation (SpO2) at rest $\leq 93 \%$, partial pressure of $\mathrm{PaO} 2 / \mathrm{FiO} 2 \leq 300 \mathrm{mmHg}$, requirement for mechanical ventilation, shock, etc. As of February 21, 2020, four patients with severe COVID-19 were recovered and discharged by MSCs therapy in China [21]. Therefore, we believe that MSCs would be a new effective therapeutic method for severe or critical COVID-19.

According to World Health Organization [22], the management of COVID-19 has mainly focused on infection prevention, case detection and monitoring, and supportive care. However, no specific anti-SARS-CoV-2 treatment is recommended because of the absence of evidence. Most importantly, the current guidelines emphasize that systematic corticosteroids should not be given routinely for COVID-19 treatment, which was also the recommendation in a Comment in The Lancet [23]. Evidence shows that MSCs can be used as a treatment without the occurrence of severe adverse events. In conclusion, it might be noteworthy to test the safety and efficacy of MSC transfusion in COVID-19 patients, especially for the severe or critical cases.

\section{Abbreviations \\ COVID-19: 2019 novel coronavirus disease; SARS-CoV-2: Severe acute respiratory syndrome coronavirus; ALI: Acute lung injure; ARDS: Acute respiratory distress syndrome; MSCs: Mesenchymal stem cells; MERS: Middle Eastern respiratory syndrome; GVHD: Graft-versus-host-disease; EVs: Extracellular vesicles}

\section{Acknowledgements}

We apologize to the authors whose work has not been cited here owing to space limitations.

\section{Authors' contributions}

$S L$ and DP contributed to the study design, data analysis and interpretation, and writing of the manuscript. HQ collected the data mentioned in the article. KY revised the manuscript. ZF and LZ contributed to the study design, financial support, data analysis and interpretation, and writing, editing and revising and final approval of the manuscript. The author(s) read and approved the final manuscript.

\section{Funding}

This work is partly financially supported by the Ministry of Science and Technology of China (2016YFA0101300) and Medical Project funded jointly by Chongqing Science and Technology Commission and Chongqing Health Commission (2018ZDXM041). The funders had no role in the study design, data collection and analysis, decision to publish, or preparation of the manuscript.

Availability of data and materials

Please contact us for the detailed data.

Ethics approval and consent to participate

Not applicable.

Consent for publication

Not applicable. 


\section{Competing interests}

The authors have no conflicts of interest to declare.

\section{Author details}

${ }^{1}$ Center for Clinical Molecular Laboratory Medicine/Newborn Screening Center National Clinical Research Center for Child Health and Disorders, Children's Hospital of Chongqing Medical University, Chongqing, China. ${ }^{2}$ Department of Respiratory Medicine; Ministry of Education Key Laboratory of Child Development and Disorders; China International Science and Technology Cooperation Base of Child Development and Critical Disorders, Children's Hospital of Chongqing Medical University, Chongqing, China. ${ }^{3}$ Chongqing Engineering Research Center of Stem Cell Therapy, Chongqing, China.

Received: 12 March 2020 Revised: 7 April 2020

Accepted: 14 April 2020 Published online: 04 May 2020

\section{References}

1. The dynamic data for COVID-19 epidemic worldwide. 2020. https://wp. m.163.com/163/page/news/virus_report/index.html. Accessed 3 Apr 2020

2. Rubenfeld GD, Caldwell E, Peabody E, et al. Incidence and outcomes of acute lung injury. N Engl J Med. 2005;353:1685-93.

3. Harrell CR, Sadikot R, Pascual J, et al. Mesenchymal stem cell-based therapy of inflammatory lung diseases: current understanding and future perspectives. Stem Cells Int. 2019;2019:4236973.

4. Fujita Y, Kadota T, Araya J, et al. Clinical application of mesenchymal stem cell-derived extracellular vesicle-based therapeutics for inflammatory lung diseases. J Clin Med. 2018;7(10):355.

5. Chen TS, Lai RC, Lee MM, et al. Mesenchymal stem cell secretes microparticles enriched in pre-microRNAs. Nucleic Acids Res. 2010;38(1): 215-24.

6. Lai RC, Tan SS, Teh BJ, et al. Proteolytic potential of the MSC exosome proteome: implications for an exosome-mediated delivery of therapeutic proteasome. Int J Proteomics. 2012;2012:971907.

7. Aggarwal S, Pittenger MF. Human mesenchymal stem cells modulate allogeneic immune cell responses. Blood. 2005;105(4):1815-22.

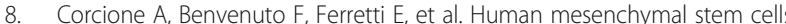
modulate B-cell functions. Blood. 2006;107(1):367-72.

9. Goolaerts A, Pellan-Randrianarison N, Larghero J, et al. Conditioned media from mesenchymal stromal cells restore sodium transport and preserve epithelial permeability in an in vitro model of acute alveolar injury. Am J Physiol Lung Cell Mol Physiol. 2014;306(11):L975-85.

10. Krasnodembskaya A, Song $Y$, Fang $X$, et al. Antibacterial effect of human mesenchymal stem cells is mediated in part from secretion of the antimicrobial peptide LL-37. Stem Cells. 2010;28(12):2229-38.

11. Islam MN, Das SR, Emin MT, et al. Mitochondrial transfer from bone-marrowderived stromal cells to pulmonary alveoli protects against acute lung injury. Nat Med. 2012;18(5):759-65.

12. Force ADT, Ranieri VM, Rubenfeld GD, et al. Acute respiratory distress syndrome: the Berlin definition. JAMA. 2012;307(23):2526-33.

13. Wilson JG, Liu KD, Zhuo H, et al. Mesenchymal stem (stromal) cells for treatment of ARDS: a phase 1 clinical trial. Lancet Respir Med. 2015;3(1):2432

14. Lee JW, Fang X, Gupta N, et al. Allogeneic human mesenchymal stem cells for treatment of $E$. coli endotoxin-induced acute lung injury in the ex vivo perfused human lung. Proc Natl Acad Sci U S A. 2009;106(38):16357-62.

15. Laffey JG, Matthay MA. Fifty years of research in ARDS. Cell-based therapy for acute respiratory distress syndrome. Biology and potential therapeutic value. Am J Respir Crit Care Med. 2017;196(3):266-73.

16. Morata-Tarifa C, Macias-Sanchez MDM, Gutierrez-Pizarraya A, SanchezPernaute R. Mesenchymal stromal cells for the prophylaxis and treatment of graft-versus-host disease-a meta-analysis. Stem Cell Res Ther. 2020;11(1):64.

17. Li Y, Xu J, Shi W, et al. Mesenchymal stromal cell treatment prevents H9N2 avian influenza virus-induced acute lung injury in mice. Stem Cell Res Ther. 2016;7(1):159.

18. Chan MC, Kuok DI, Leung CY, et al. Human mesenchymal stromal cells reduce influenza a $\mathrm{H} 5 \mathrm{~N} 1$-associated acute lung injury in vitro and in vivo. Proc Natl Acad Sci U S A. 2016;113(13):3621-6.

19. Khatri M, Richardson LA, Meulia T. Mesenchymal stem cell-derived extracellular vesicles attenuate influenza virus-induced acute lung injury in a pig model. Stem Cell Res Ther. 2018;9(1):17.
20. Simonson OE, Mougiakakos D, Heldring N, et al. In vivo effects of mesenchymal stromal cells in two patients with severe acute respiratory distress syndrome. Stem Cells Transl Med. 2015;4(10):1199-213.

21. News conference for joint prevention and control measure of COVID-19 by China's State Council. 2020. https://v.qq.com/x/page/m3069nonfb4.html. Accessed 3 Mar 2020.

22. WHO. Clinical management of severe acute respiratory infection when novel coronavirus (nCoV) infection is suspected. 2020. https://www.who.int/ docs/default-source/coronaviruse/clinical-management-of-novel-cov.pdf. Accessed 29 Feb 2020

23. Russell CD, Millar JE, Baillie JK. Clinical evidence does not support corticosteroid treatment for 2019-nCoV lung injury. Lancet. 2020;395(10223): 473-5.

\section{Publisher's Note}

Springer Nature remains neutral with regard to jurisdictional claims in published maps and institutional affiliations. 